\title{
EMIC waves observed by Cluster near the plasmapause
}

\author{
Y. H. Liu, ${ }^{1,2}$ B. J. Fraser, ${ }^{2}$ and F. W. Menk ${ }^{2}$ \\ Received 7 May 2013; revised 28 July 2013; accepted 30 July 2013; published 12 September 2013.
}

[1] We analyze a long-duration electromagnetic ion cyclotron (EMIC) wave event seen in the inner magnetosphere in order to understand the propagation characteristics of these waves in the vicinity of the plasmapause. The study takes advantage of the south to north orbit of the four-satellite Cluster constellation as it passed through perigee at $L \sim 4.2$ at $\sim 08$ magnetic local time on 2 November 2001. Cluster traversed from a low-density magnetosphere $\left(<20 \mathrm{~cm}^{-3}\right)$ through a gradual plasmapause into a high-density plasmasphere $\left(\sim 80 \mathrm{~cm}^{-3}\right)$ where the waves were seen over about $50 \mathrm{~min}$ and ceased on exiting the plasmapause in the Northern Hemisphere. The waves were observed over $1.8-3.5 \mathrm{~Hz}$, above the local helium cyclotron frequency, between magnetic latitudes $\pm 18^{\circ}$, and confined to a radial source region size estimated at $0.77 R_{E}$. Wave polarization appeared to be associated with plasma density, with left hand in the equatorial region, right hand at higher latitudes nearer the plasmapause, and a mixture between. Wave normal angles were typically $<60^{\circ}$, and Poynting flux measurements show that wave energy was predominantly directed along the geomagnetic field toward high latitudes in both hemispheres. These results suggest that the plasma density and its gradient play a significant role in confining the wave source region and affecting the wave properties, which will help understand wave generation and propagation mechanisms in the magnetosphere plasma environment.

Citation: Liu, Y. H., B. J. Fraser, and F. W. Menk (2013), EMIC waves observed by Cluster near the plasmapause, J. Geophys. Res. Space Physics, 118, 5603-5615, doi:10.1002/jgra.50486.

\section{Introduction}

[2] Electromagnetic ion cyclotron (EMIC) waves in the Pc1-2 ULF wave band with frequencies in the range 0.1$5.0 \mathrm{~Hz}$ are generated by $10-100 \mathrm{keV}$ ring current protons in the equatorial magnetosphere through the ion cyclotron instability [e.g., Cornwall, 1965]. Satellite observations in the middle magnetosphere and at the geostationary orbit have shown that EMIC waves are usually left-hand polarized, although linear and right-hand polarizations may occur in the presence of heavy ions [Mauk and McPherron, 1980; Young et al., 1981]. The dispersion relation for EMIC waves propagating parallel to the ambient magnetic field in a cold proton $\left(\mathrm{H}^{+}\right)$electron $\left(\mathrm{e}^{-}\right)$plasma shows that the interacting protons have a minimum parallel energy at the geomagnetic equator, where the ambient magnetic field is a minimum, supporting the idea that the equatorial region is favored for EMIC wave generation [Mauk, 1982; Hu et al., 1990]. The convective wave growth rate will maximize where the group velocity and the Alfvén velocity are a minimum, so the favored region will again be near the equator [Fraser et al., 1992].

\footnotetext{
${ }^{1}$ Department of Polar Atmosphere and Space Physics, Polar Research Institute of China, Shanghai, China.

${ }^{2}$ Center for Space Physics, University of Newcastle, Callaghan, New South Wales, Australia.

Corresponding author: Y. H. Liu, Polar Research Institute of China, Shanghai 200129, China. (liuyonghua@hotmail.com)

(C)2013. American Geophysical Union. All Rights Reserved. 2169-9380/13/10.1002/jgra.50486
}

[3] It has been suggested that EMIC wave occurrence will increase near the plasmapause, which is the preferred source location for the convective amplification of EMIC waves [Horne and Thorne, 1993]. Here the steep radial plasma density gradient may enable guided waves to grow over several equatorial passes with increasing wave gain [Horne and Thorne, 1993]. During the recovery phase of a magnetic storm, the ring current will overlap with the plasmapause, and wave growth should be strongest just inside the plasmapause since the high plasma density should reduce the phase velocity and thus enable the waves to resonate with the bulk of the ion distribution [Cornwall et al., 1970].

[4] Although EMIC wave generation theory suggests that EMIC waves are more likely to be seen near the plasmapause [Horne and Thorne, 1993], elliptically orbiting satellite observations show that more waves are seen in the plasmatrough region than in the plasmasphere [Anderson et al., 1992a, 1992b; Fraser and Nguyen, 2001]. However, the role of the plasmapause is still unclear experimentally with Fraser and Nguyen [2001] finding no preference for waves at the plasmapause, while Fraser et al. [1992] provided details of an event observed within a broad and gradual plasmapause.

[5] The plasmasphere resides in the dipolar portion of the Earth's magnetosphere and is filled with a cold dense $(\sim \mathrm{eV})$ plasma population [Lemaire and Gringauz, 1998; Borovsky and Denton, 2008, and references therein]. The plasmapause is the boundary of the plasmasphere exhibiting a steep plasma density gradient, which results from the corotating plasmasphere interacting with the stationary plasmatrough plasma region [Nishida, 1966]. The plasmapause has a bulge 


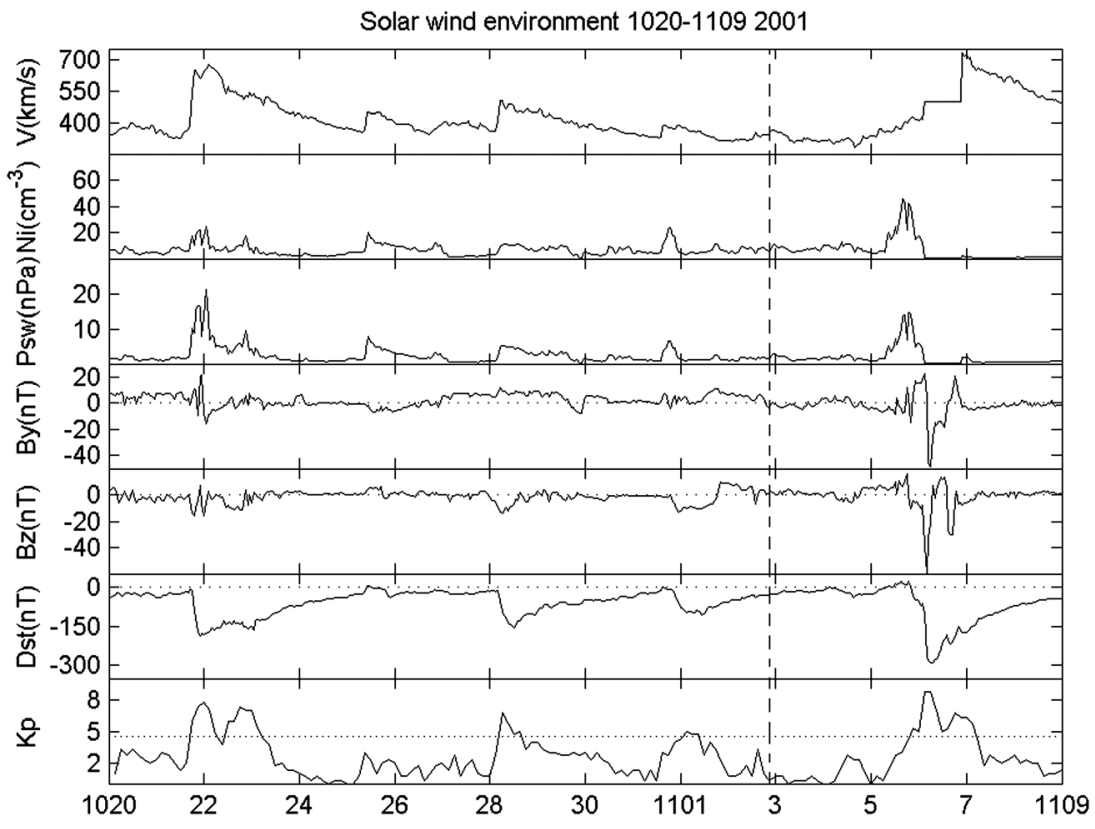

Figure 1. Solar wind environment from 20 October to 09 November 2001. The panels from top to bottom show data on the solar wind velocity $(V)$, density $(\mathrm{Ni})$, dynamic pressure (Psw), interplanetary magnetic field $y$ component $(B y)$ and $z$ component $(B z)$ in GSE coordinates, $D s t$, and $K p$ index. The Pc1 waves were observed over 2110-2210 UT on 2 November 2001 after moderate substorm activity. The vertical dashed line marks the time when the Pc1 event occurred.

on the duskside sector [Carpenter, 1963; Carpenter and Anderson, 1992], and the outer edge of the plasmasphere becomes decoupled, resulting in detached plasma patches [Chappell, 1974]. It is now known that these are attached dense cold plasma plumes, radially extended from the plasmapause [Sandel et al., 2001].

[6] ISEE and Viking in situ satellite observations have found EMIC waves just inside the plasmapause [Fraser et al., 1992; Erlandson et al., 1992, 1996]. These EMIC waves occurred over a wide range of magnetic local time (MLT), including the duskside, early morning, and prenoon, over $L=3.6-5.5$. The relationship of these waves to the plasmapause was determined by simultaneous observations of the EMIC waves and the cold plasma density. Erlandson et al. [1992] found that the most intense EMIC waves were observed at the plasmapause, while smaller amplitude waves were observed in the plasmasphere. Fraser et al. [1992] concluded that EMIC waves were observed in a thick plasmapause as well as the outer plasmasphere during the refilling phase following substorm activity. Poynting flux results from these studies indicated that the wave energy either generally propagated downward toward the ionosphere [Erlandson et al., 1992] or has both parallel and antiparallel directions with respect to the magnetic field [Fraser et al., 1992]. These propagation characteristics are also supported by a statistical study based on CRRES measurements [Loto'aniu et al., 2005]; Loto'aniu et al. [2005] further noted that the source region is restricted to within $\pm 11^{\circ}$ in magnetic latitude (MLAT). That study covered EMIC waves that were observed over a radial wider range of $L=3.5-8$ and so was not limited to the plasmapause. It has also been noted that very few "pearl" or structured Pc1 waves are seen by satellites.

[7] In this paper, we take advantage of the magnetic, electric, and plasma observations from the four Cluster satellites which form a tetrahedron, with separations providing a convenient configuration to study temporal and spatial variations and to investigate a typical fine-structured EMIC wave event. The Cluster satellites traveled northward across their perigees at $L \sim 4.2$ Earth radii $\left(R_{E}\right)$ just inside the plasmapause. Observations of wave and plasma properties show that the EMIC waves were localized and occurred in regions with significantly increased electron density. EMIC wave observations in this region using Cluster and associated with ground observations and proton precipitation were previously reported by Usanova et al. [2010], while Pickett et al. [2010] studied the wave characteristics of a similar Cluster event. Here we will show that the EMIC wave event is confined to the high-density plasmasphere-plasmapause regions, and we describe the role played by the multi-ion background plasma in determining the wave propagation characteristics.

\section{Solar Wind Environment}

[8] The solar wind environment at the Earth's orbit (from the OMNI data set based on observations from satellites in the upstream solar wind, including ACE, Wind, etc., provided by the NASA-GSFC Data Center) is summarized in Figure 1. Several magnetic storms/substorms occurred in late October and early November 2001, and the minimum Dst values on 21 October, 28 October, 1 November, and 6 November were $-184,-157,-106$, and $-292 \mathrm{nT}$, respectively. The first three storms can be regarded as moderate storms, while the last one may be classified as an intense storm. The EMIC waves discussed here were detected on 2 November during the recovery stage of the 1 November storm. All the storms responded to the negative interplanetary magnetic field (IMF) $B z$, the south-north component of the interplanetary magnetic field. Corresponding to the storms, we can also see a varying 


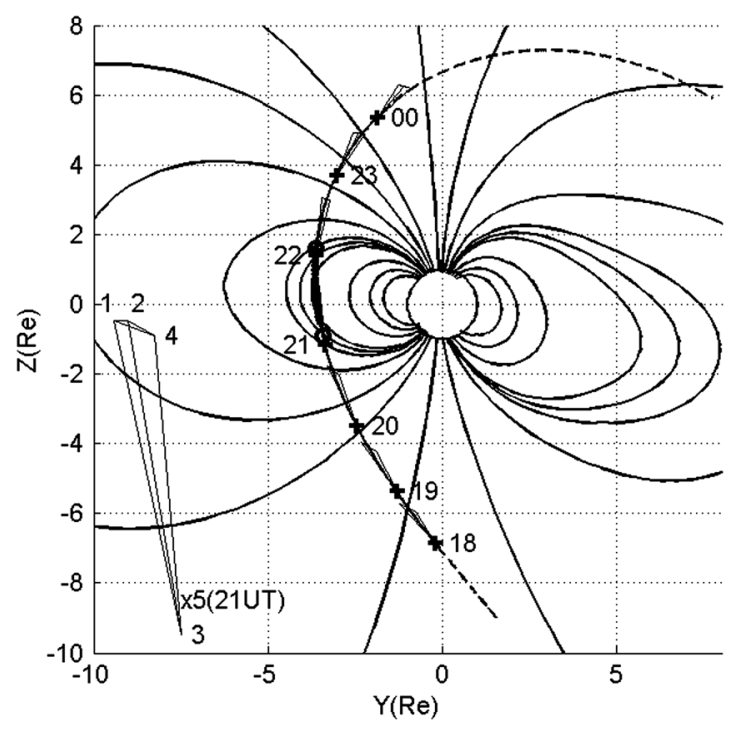

Figure 2. Cluster orbit and magnetospheric configuration in the $Y$-Z plane on 2 November 2001 based on calculations from the Tsyganenko [1996] model (T-96). The coordinates are shown in the geocentric solar magnetic (GSM) system and in Earth radii. Universal time is indicated by the labels 18-00 (UT), and the location of satellite C3 is denoted by plus symbols. The circles identify the entry and exit from the plasmapause. The tetrahedrons represent the formation of the four Cluster satellites. The distances between the satellites at 2100 UT are enlarged by 5 times and shown at the left bottom corner, where the digital numbers denote the Cluster satellites. The Pc1 waves were observed in the time interval 2100-2210 UT marked by the thick solid line.

enhancement of the solar wind dynamic pressure (Psw). However, Psw was stable at $2 \mathrm{nPa}$ when the EMIC waves occurred on 2 November. It therefore appears that this EMIC wave event was not associated with magnetospheric compression, though it appeared on the early dayside at $\sim 08$ MLT.

\section{Instrumentation}

[9] Three data sets were used to study the EMIC waves: magnetic field data, electric field data, and electron density data. These were obtained, respectively, by the fluxgate magnetometer (FGM), the electric field and wave (EFW) instrument [Gustafsson et al., 2001], and the WHISPER (Waves of High frequency and Sounder for Probing of the Electron density by Relaxation) instrument [Décréau, 2001]. These experiments are common to all four spacecraft in the Cluster mission, which were launched in July 2000 into a polar orbit, with an orbital period of $57 \mathrm{~h}$ and perigee and apogee of 4.0 and $19.6 R_{E}$, respectively [Escoubet et al., 2001]. The magnetometer data were sampled at $64 \mathrm{~Hz}$ [Balogh et al., 1997] in the geocentric solar ecliptic (GSE) coordinate system, here resampled at $20 \mathrm{~Hz}$ and transformed to a field-aligned coordinate system (FAS) for EMIC wave analysis. The FAS system has the $z$ axis directed along the geomagnetic field mean direction that is derived by averaging over 600 data points covering a $30 \mathrm{~s}$ time interval. The $y$ axis is determined by $\hat{z} \times \hat{r}$, perpendicular to the $\hat{z}$ direction and directed east, and the $x$ axis is given by $\hat{y} \times \hat{z}$, pointing outward in the magnetosphere, completing the triad. Here $\hat{r}$ is the unit vector of Earth radii pointing out of the Earth. The EFW electric fields were measured at $25 \mathrm{~Hz}$ and here resampled at $20 \mathrm{~Hz}$ when used to estimate the Poynting flux vector of Pc1 waves. WHISPER, an active sounder, observes resonances in the $2-80 \mathrm{kHz}$ band. Of particular interest is the electron plasma frequency $\left(f_{\mathrm{pe}}\right)$, which provides the total electron density $n_{e} \approx 1 / 81 f_{p e}{ }^{2}\left(f_{p e}\right.$ is in kilohertz, and $n_{e}$ is in units per cubic centimeter) [Moullard et al., 2002]. The electron density is used to identify the location of the Cluster satellites with respect to the magnetosphere and plasmasphere and associated boundaries as well as contribute to the understanding of the propagation mechanisms of the EMIC waves.

\section{Observations}

[10] In this section, we will present data on the 2 November 2001 EMIC wave event, including associated plasma properties along with wave propagation properties which show that the waves only propagated in the dense outer plasmasphereplasmapause regions.

\subsection{The Cluster Orbit}

[11] The EMIC waves on 2 November 2001 were recorded by the Cluster satellites near 08 MLT over 2100-2210 UT when they moved northward across perigee at $L=4.1$ from the Southern Hemisphere to the Northern Hemisphere through the outer plasmasphere near the plasmapause, as shown in Figure 2. The two circles indicate the beginning and the end of the enhanced total electron density region observed by WHISPER, corresponding to entry and exit from the plasmasphere through the plasmapause. The magnetic field is derived from the Tsyganenko [1996] model under the solar wind conditions prevailing at the time, and field lines near the circles can roughly be regarded as the region close to the plasmapause. The tetrahedron formed by the four Cluster satellites was extended greatly in the north-south direction, with $\mathrm{C} 1 / \mathrm{C} 2 / \mathrm{C} 4$ closely spaced at 1620 and $\mathrm{C} 3$ spaced at $11,500 \mathrm{~km}$ away. C3 passed through perigee about $45 \mathrm{~min}$ later than $\mathrm{C} 1 / \mathrm{C} 2 / \mathrm{C} 4$. The Cluster tetrahedron in Figure 2 and the plot in Figure 3 show that $\mathrm{C} 1$ was radially farthest from

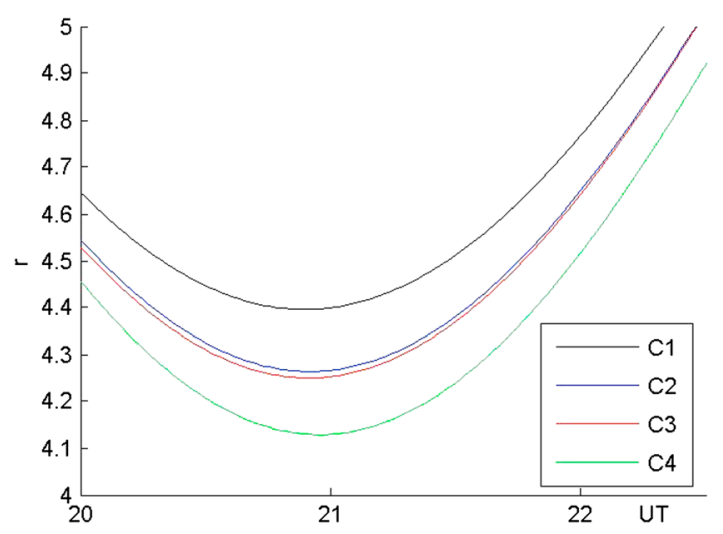

Figure 3. Distances from the Cluster spacecraft to the Earth's center from 2000 to 2230 UT on 2 November 2001. Note that the data points from C3 have already been shifted $45 \mathrm{~min}$ earlier since $\mathrm{C} 3$ passed its perigee at $2140 \mathrm{UT}$, 45 min later than $\mathrm{C} 1, \mathrm{C} 2$, and $\mathrm{C} 4$ at $2055 \mathrm{UT}$. 
Table 1. Cluster Perigee Parameters

\begin{tabular}{lcc}
\hline & $r\left(R_{E}\right)$ & Time (UT) \\
\hline C1 & 4.396 & 2054 \\
C2 & 4.264 & 2055 \\
C3 & 4.250 & 2140 \\
C4 & 4.129 & 2058 \\
\hline
\end{tabular}

the Earth, followed by $\mathrm{C} 2 / \mathrm{C} 3$, with $\mathrm{C} 4$ closest to the Earth. The radial distances of C1, C2, C3, and C4 are 4.396, 4.264, 4.250, and 4.129 $R_{E}$, respectively, at the times indicated in Table 1. This provides an excellent geometry to investigate the spatial and temporal properties of EMIC waves.

\subsection{Plasma Density}

[12] The Cluster WHISPER total electron density experiment provides information on when and where Cluster enters and leaves the plasmasphere. Figure 4 shows that on 2 November, the total electron density increased from 2030 to 2130 UT at C1, C2, and C4 and from 2115 to 2215 UT at $\mathrm{C} 3$. This indicates that $\mathrm{C} 1, \mathrm{C} 2$, and $\mathrm{C} 4$ passed through the plasmasphere about 45 min earlier than $\mathrm{C} 3$, in agreement with Cluster's tetrahedron configuration (Figures 2 and 3). There are significant differences in the magnitude of the electron density seen at the satellites. The maximum electron density is $<40 \mathrm{~cm}^{-3}$ at $\mathrm{C} 1$, near $60 \mathrm{~cm}^{-3}$ at $\mathrm{C} 2$, reaching $80 \mathrm{~cm}^{-3}$ at $\mathrm{C} 3$ though variable, and stable at $80 \mathrm{~cm}^{-3}$ at $\mathrm{C} 4$. It is important to note that the WHISPER experiment saturates for electron densities $>80 \mathrm{~cm}^{-3}$ [Remè et al., 2001], which occurred at $\mathrm{C} 4$ in the time interval $2010-2110$ UT. The EMIC waves seen at the satellites occurred within the enhanced electron density region denoted by the horizontal bars in Figure 4. At $\mathrm{C} 1, \mathrm{C} 2$, and $\mathrm{C} 4$, the waves occurred when the satellites exited through the gradual plasmapause, while at $\mathrm{C} 3$, these waves occurred throughout the satellite's time in the plasmapause/ plasmasphere.

\subsection{Wave Spectra}

[13] The dynamic spectra of the wave event are shown in Figure 5a for $\mathrm{C} 1, \mathrm{C} 2$, and $\mathrm{C} 4$. The event occurred in the frequency range $2.3-3.1 \mathrm{~Hz}$, within the plasmasphere or on the Northern Hemisphere plasmapause at $\sim 08$ MLT, over $L \sim 4.1-4.9$ and $5.2^{\circ}-17.5^{\circ}$ MLAT. In contrast, Figure $5 \mathrm{~b}$ shows that $\mathrm{C} 3$ saw the waves over $2.0-3.3 \mathrm{~Hz}$ throughout its pass through the plasmasphere from $-13.5^{\circ}$ to $16^{\circ} \mathrm{MLAT}$ at $L \sim 4.2-4.6$.

[14] The dynamic spectra from $\mathrm{C} 1, \mathrm{C} 2$, and $\mathrm{C} 4$ show two wave packet groups, around 2110 and 2120 UT, respectively (Figure 5a). In Figure 5a, the two wave packet groups show obviously different signatures among the three satellites. At $\mathrm{C} 1$, the first wave group dominates, and the second group is weak, especially on the transverse components. Similarly, at $\mathrm{C} 2$, the first wave group has higher spectral power, but the second group has increased power compared with the corresponding $\mathrm{C} 1$ group. For $\mathrm{C} 4$, the second packet group is more intense than the first. At $\mathrm{C} 1$, the first packet group started at 2103 UT, about 2 min earlier than at C4. The second wave packet at $\mathrm{C} 4$ disappeared after 2125 UT but remained active until $2128 \mathrm{UT}$ at C3 (Figures 5a and 5b). At C3, at least four wave packet groups were recorded, over 2115-2128, 2129-2145, and 2147-2205 UT around $2.8 \mathrm{~Hz}$ and 21262135 UT around $3.1 \mathrm{~Hz}$. The first packet group at C3 was observed at the same time as the second group seen at $\mathrm{C} 1, \mathrm{C} 2$, and C4 over 2117-2125 UT. The other wave packet groups at $\mathrm{C} 3$ were not seen at $\mathrm{C} 1, \mathrm{C} 2$, and $\mathrm{C} 4$. These signatures of the wave packets should relate to locations of the satellites

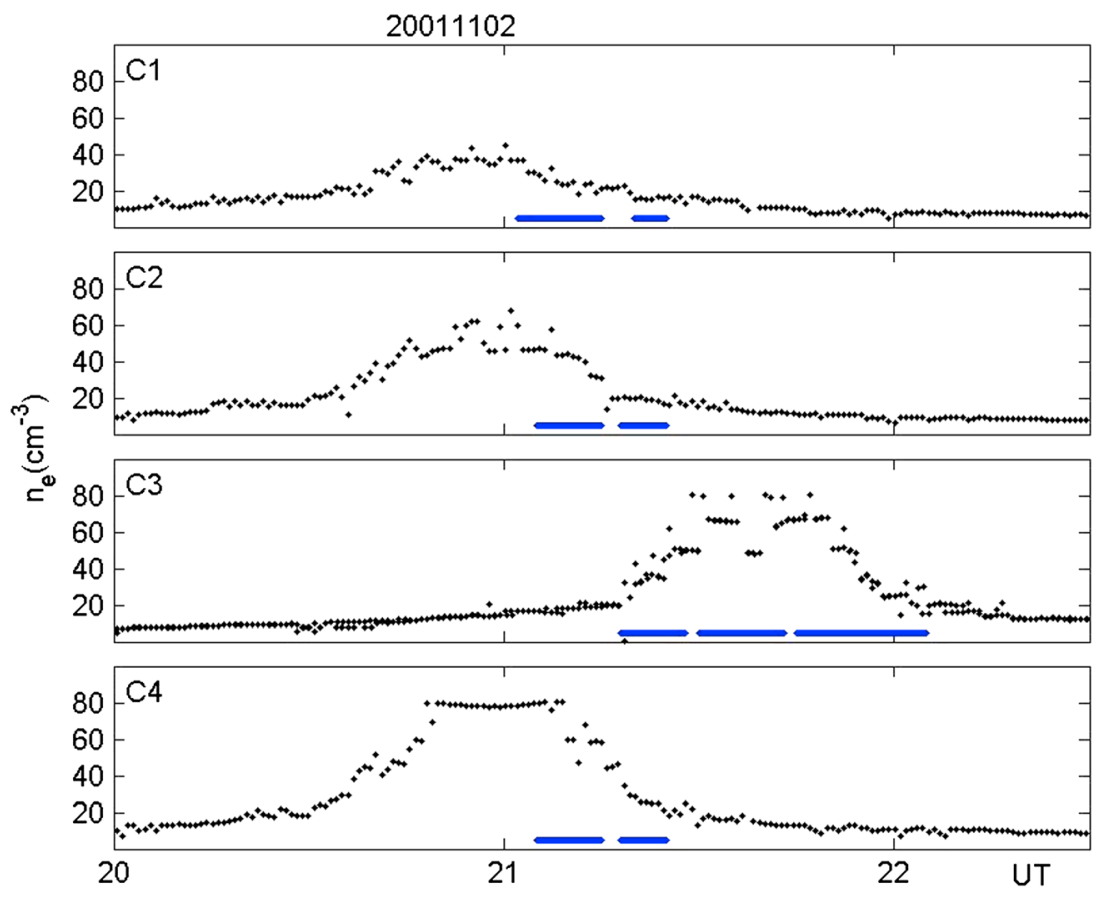

Figure 4. Total electron density during 2000-2230 UT on 2 November 2001 derived from the WHISPER observations on the Cluster spacecraft. The panels from top to bottom show results from $\mathrm{C} 1, \mathrm{C} 2, \mathrm{C} 3$, and $\mathrm{C} 4$, respectively. The horizontal bars indicate the time intervals when the Pc1 waves were observed by the corresponding spacecraft. 

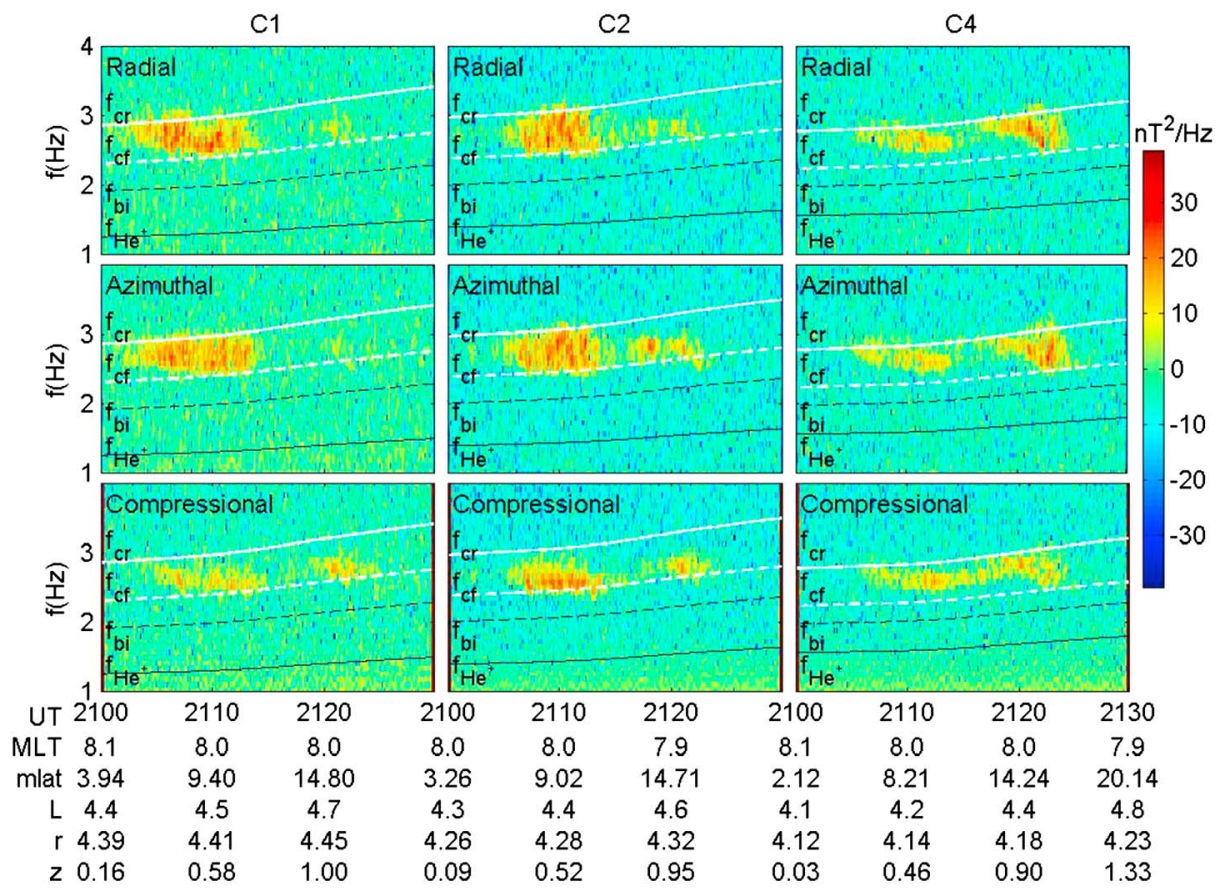

a

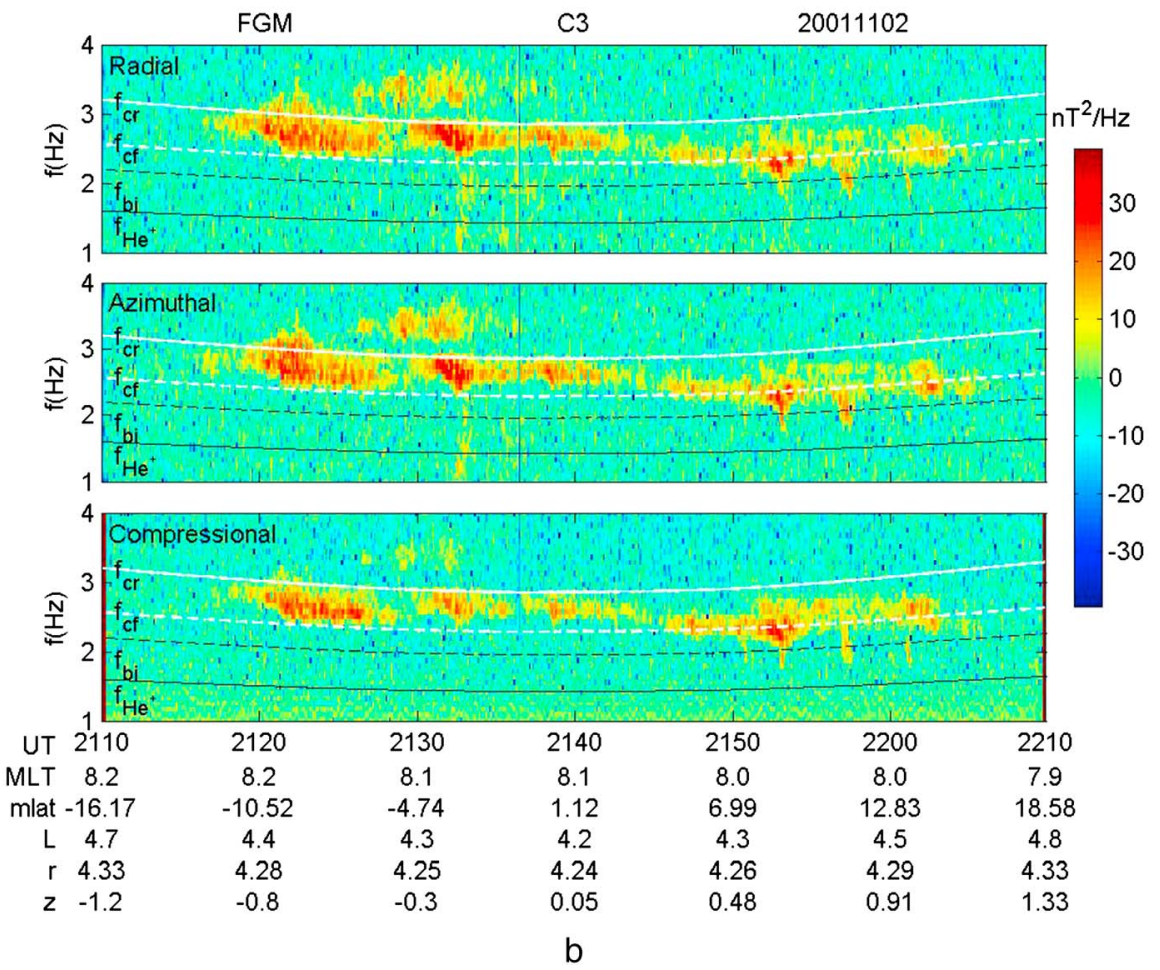

Figure 5. (a) Dynamic spectra of Pc1 waves recorded by the FGM instrument at the first, second, and fourth Cluster spacecraft (C1, C2, and C4) over 2100-2130 UT on 2 November 2001. The magnetic data have been transformed into the local field-aligned coordinate system. The dashed and solid lines plotted represent (in order of increasing frequency) the local helium cyclotron frequency $\left(f_{\mathrm{He}^{+}}\right)$, the computed bi-ion frequency $\left(f_{\mathrm{bi}}\right)$, the helium cutoff frequency $\left(f_{\mathrm{cf}}\right)$, and the helium crossover frequency $\left(f_{\mathrm{cr}}\right)$, as described in section 5.3. MLT and $L$ values are derived from the Tsyganenko [1996] model (T-96) under normal conditions, MLAT is the magnetic latitude in the magnetic dipole system derived from the T-96 model under real conditions, and the $r$ and $z$ data are calculated from the Cluster orbit position in the geocentric solar magnetic (GSM) system and in Earth radii. (b) Similar to Figure 5a but for C3. The time interval is 2110-2210 UT. 
LIU ET AL.: EMIC WAVES NEAR THE PLASMAPAUSE
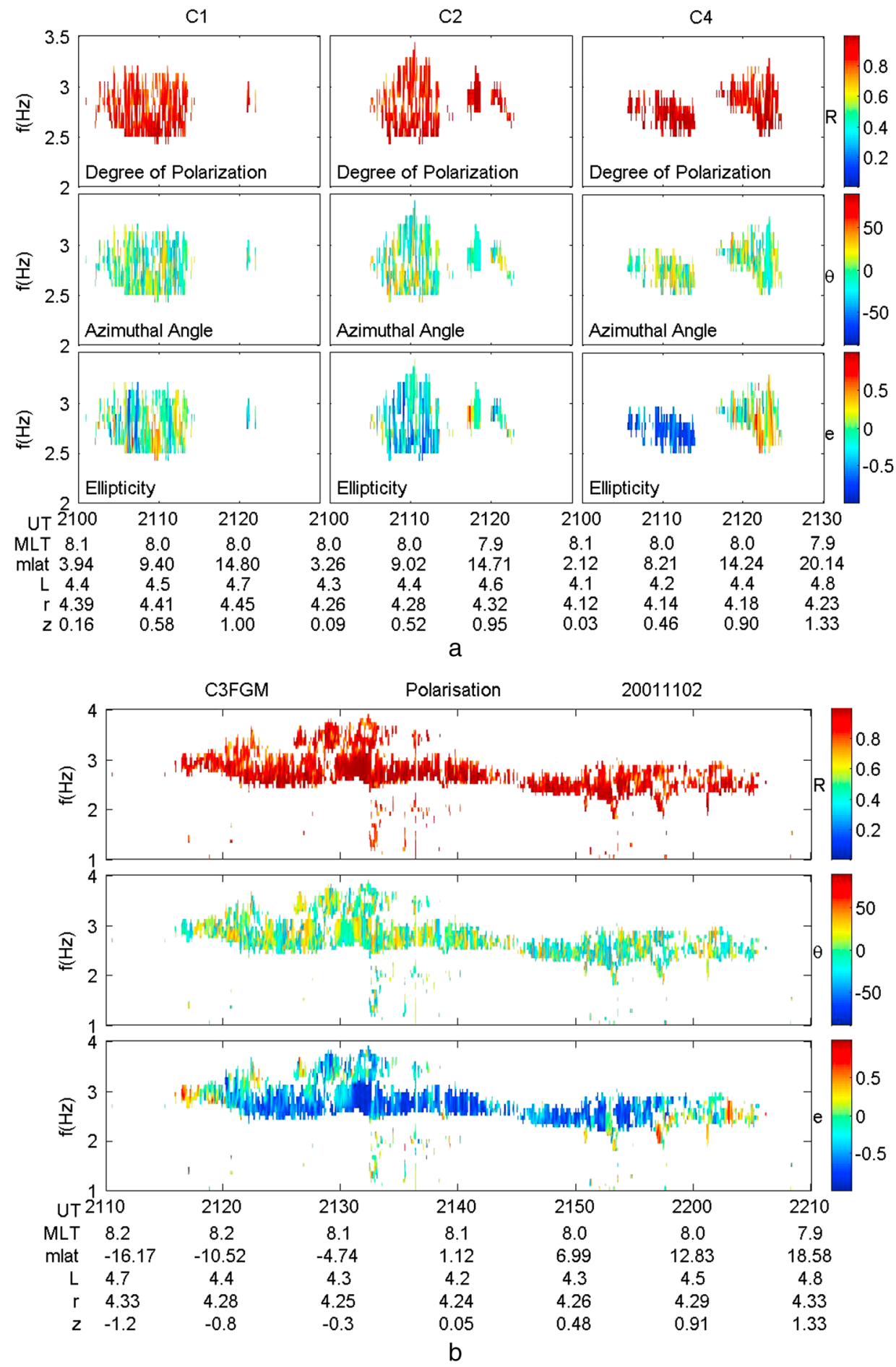

Figure 6. (a) Dynamic spectra of polarization of Pc1 waves recorded by the FGM instrument on C1, C2, and C4 over 2100-2130 UT on 2 November 2001. (b) Similar to Figure 6a but for C3. The time interval is 2110-2210 UT.

relative to the plasmasphere/plasmapause and determined by the plasma density and the $B$ field, which will be clarified in detail later in section 5 .

\subsection{Wave Polarization}

[15] Polarization properties are a powerful means to gain insight into the physical characteristics of waves and help understand their propagation and excitation mechanisms. Four polarization parameters, the degree of polarization $(R)$, the azimuth angle $\left(\theta^{\circ}\right)$, the ellipticity $(e)$, and the sense of ellipse rotation, have been defined and calculated according the method developed by Fowler et al. [1967]. For the polarization of the EMIC waves seen by the four satellites to be significant, the degree of polarization is required to be $>0.6$ and was usually $>0.8$. While the azimuth angle centered on the radial direction may fluctuate, the ellipticity is more consistent, as 


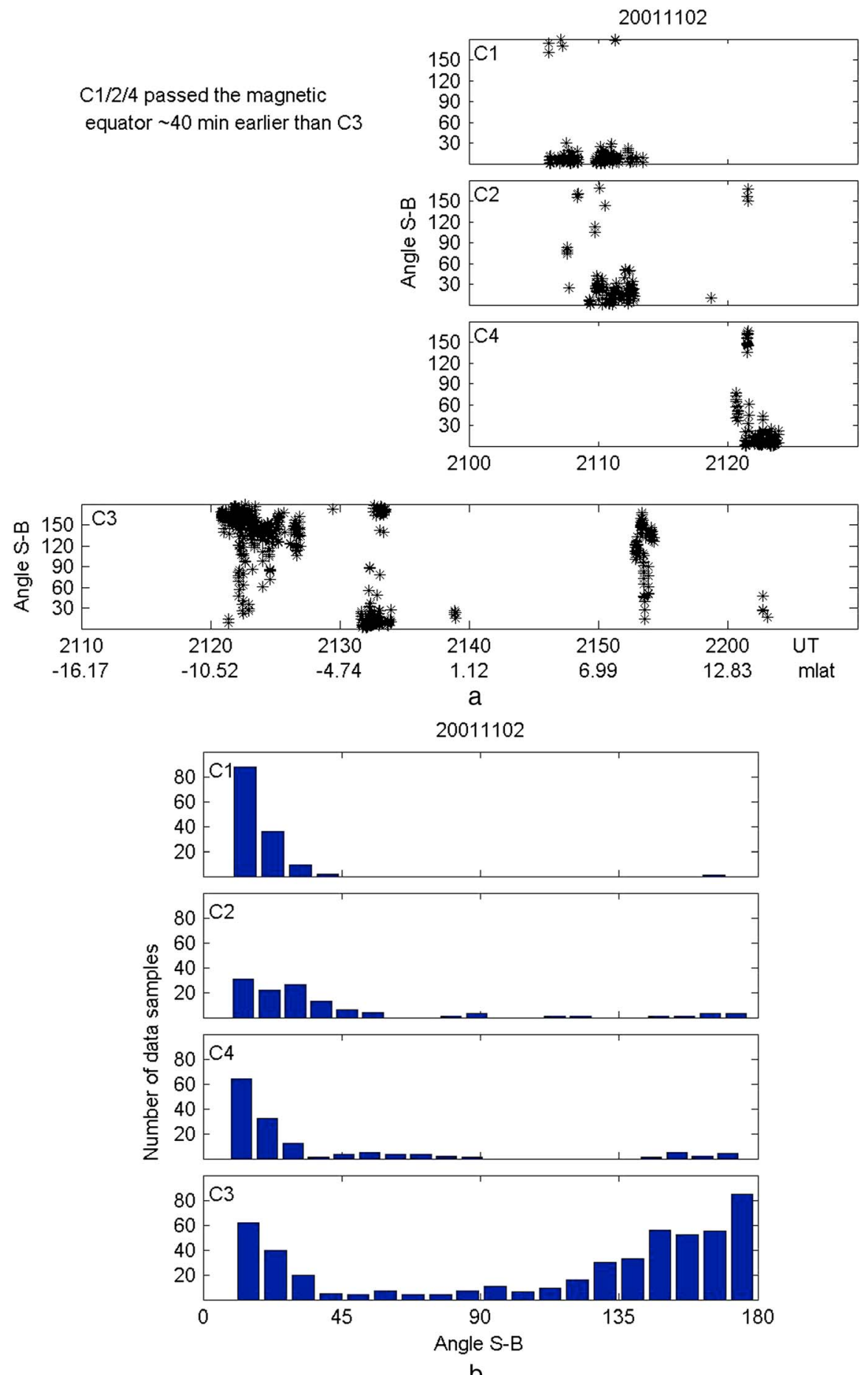

Figure 7. (a) Distribution of group ray angles between the Poynting flux vector of the Pc1 waves and the magnetic field direction over 2100-2210 UT on 2 November 2001. The Poynting flux vectors dominantly point away from the geomagnetic equator. (b) Occurrence of group ray angles between the Poynting flux vector of the Pc1 waves and the geomagnetic field direction over 2100-2210 UT, 02 November 2002.

The Poynting flux vectors are dominantly along the magnetic field direction.

illustrated in Figures $6 \mathrm{a}$ and $6 \mathrm{~b}$. At $\mathrm{C} 1$, the sense of polarization mostly is linear and left hand with 2 min of right hand at 2110 UT over $2.5-2.7 \mathrm{~Hz}$. At C2, more dominant left-hand polarization is seen in the first wave packet group before 2115 UT, while in the second wave packet group, right-hand polarization appears at 2019 UT. At C4, the waves are left hand in the first wave packet group and the initial part of the second wave group, but changed to right hand or linear after 2120 UT.

[16] At C3 (Figure 6b), the waves are predominantly left hand, except for the start and the end of the event when they show some right-hand polarization. In particular, the first wave packet group seen at $\mathrm{C} 3$ changed from right hand to left 

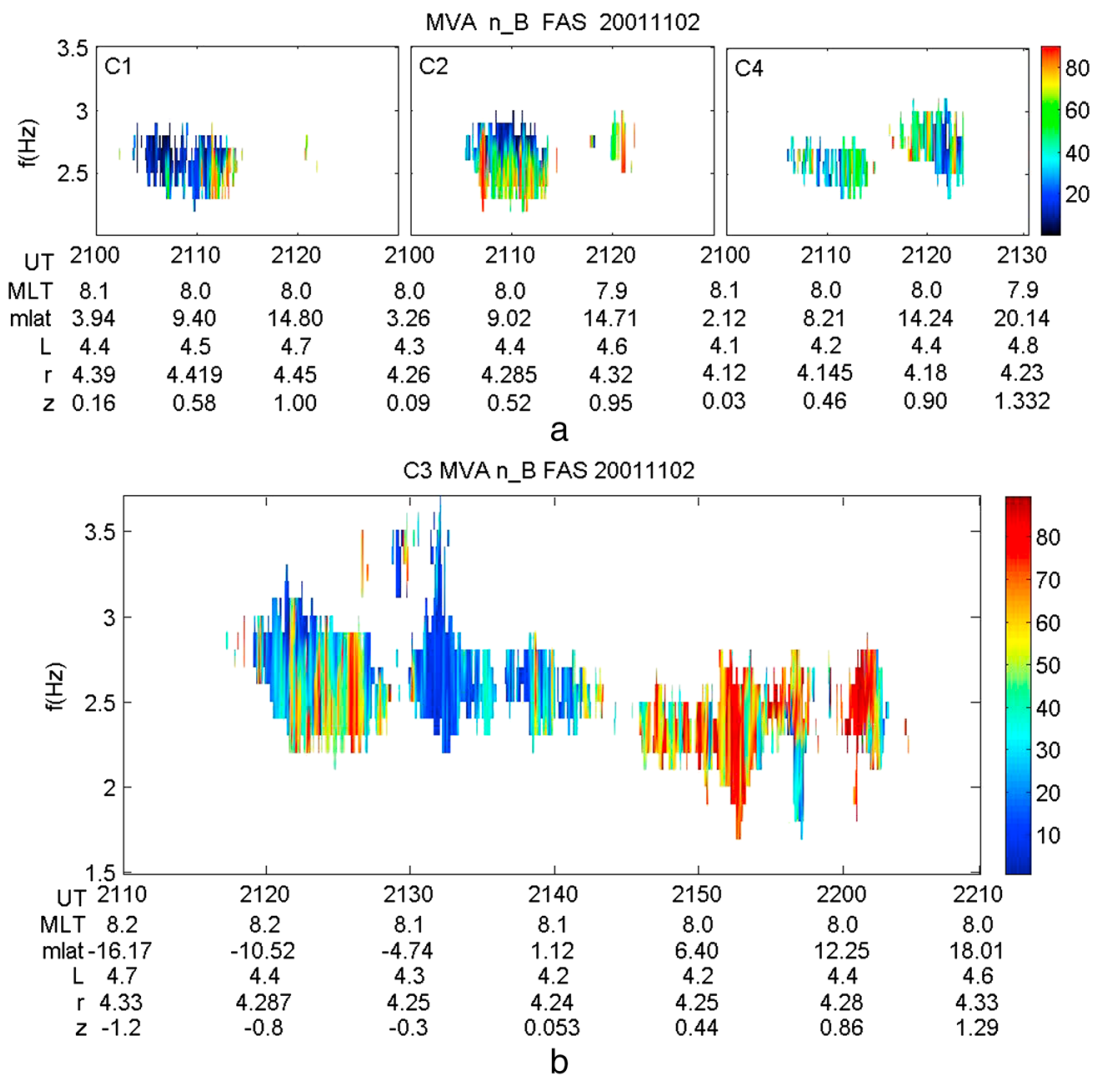

Figure 8. (a) Dynamic spectra of angles between the minimum variance direction and the magnetic field direction from C1, C2, and C4 over 2100-2130 UT on 2 November 2001. (b) Similar to Figure 8a but over 2110-2210 UT for C3.

hand at $2118 \mathrm{UT}$, which is the opposite to that seen at $\mathrm{C} 4$, where the wave polarization changed from left hand to right hand at 2122 UT. It is interesting to note that these polarization reversals were seen when $\mathrm{C} 3$ and $\mathrm{C} 4$, respectively, entered and left the plasmasphere through the plasmapause (Figure 4). This will be considered in more detail in section 5.

\subsection{Poynting Flux}

[17] The Poynting vector represents the energy flux in a wave and the direction of energy propagation, $S=\left(1 / \mu_{0}\right)$ $(\delta E \times \delta B)$, where $S$ is the Poynting vector, $\delta E$ is the wave electric field vector, and $\delta B$ is the wave magnetic field vector. $\mu_{0}$ is the magnetic permeability in free space. The procedure employed here follows that of Loto'aniu et al. [2005].

[18] Figures $7 \mathrm{a}$ and $7 \mathrm{~b}$ show that the Poynting flux vector magnitude and direction of the EMIC waves are directed mainly along the magnetic field direction, away from the magnetic equator. The Poynting flux vectors seen at $\mathrm{C} 1, \mathrm{C} 2$, and C4 are primarily directed toward the Northern Hemisphere at group ray angles generally $<30^{\circ}$ with respect to the geomagnetic field, as shown in the first three panels in Figures 7a and $7 \mathrm{~b}$. There are just a few waves with energy directed into the Southern Hemisphere. At C3, more variation in the direction of the Poynting vector can be seen, particularly close to the magnetic equator, while in the region around $\pm 10^{\circ}$ MLAT, the vectors are mainly directed away from the equator, with angles larger than $120^{\circ}$ into the Southern Hemisphere and smaller than $30^{\circ}$ into the Northern Hemisphere. These results agree with Loto'aniu et al. [2005], who identified a source region within $\pm 11^{\circ}$ MLAT of the geomagnetic equator.

\subsection{Wave Normal Direction}

[19] The wave normal directions were obtained from the minimum variance directions (MVDs) of the EMIC waves and calculated from the magnetic field vector data following the principles of Sonnerup and Cahill [1967]. Results for $\mathrm{C} 1, \mathrm{C} 2$, and $\mathrm{C} 4$ are plotted in Figure $8 \mathrm{a}$ and indicate that for the wave train seen at $\mathrm{C} 1$ before $2111 \mathrm{UT}$, the wave normal directions are typically along the geomagnetic field direction with angles $<30^{\circ}$. Oblique propagation of the waves appears at the end of the wave train at $\mathrm{C} 1$ and later in parts of the wave trains at $\mathrm{C} 3$ (Figure $8 \mathrm{~b}$ ). At C2, the MVDs vary with frequency for the first wave packet train, with low angles at higher frequencies and oblique angles at lower frequencies, as seen in the middle panel in Figure 8a. This trend is also seen at C1 after 2111 UT. C4 shows a trend similar to $\mathrm{C} 1$, with an increase in the MVDs with time (right panel in Figure 8a). Small angles are seen at C3 over 2120-2125 and 2130-2144 UT (Figure 8b). At later times at C3, 2145-2205 UT, larger angles dominate (Figure 8b).

\section{Analysis and Discussion}

[20] This Pc1 wave event was recorded by the four Cluster satellites around perigee near $L=\sim 4.2$ in the equatorial plane, where the plasmapause, ring current, and outer radiation belt usually overlap. To study the wave properties and the source 
region, an important advantage of this event is the tetrahedral orientation of the four Cluster satellites, that is, three satellites $\mathrm{C} 1, \mathrm{C} 2$, and $\mathrm{C} 4$ are closely spaced, forming a relatively small triangle with a maximum separation of $\sim 1620 \mathrm{~km}$ in the $y$ direction, but separated from $\mathrm{C} 3$ at a relatively large distance of $\sim 11,500 \mathrm{~km}$ in the $z$ direction (Figure 3 ). This geometry is useful when analyzing the relationship between the spatial and temporal wave properties and the associated plasma environment in these magnetospheric regions.

\subsection{Source Region}

[21] The Cluster satellites follow polar orbits and passed through perigee moving from south to north. However, there are differences in the time and location at which the four Cluster spacecraft passed through perigee (Table 1). It is worth noting two points. First, C4 was in the innermost orbit, while $\mathrm{C} 1$ was in the outermost orbit, and C2 was located between, essentially on the same field line path as C3 (Figure 3). These radial locations explain why the electron densities observed at $\mathrm{C} 1, \mathrm{C} 2, \mathrm{C} 3$, and C4 increase in that order (Figure 4). Second, C3 passed perigee $\sim 45$ min later than the other spacecraft. Electron densities from the four spacecraft attained their maximum around perigee at the magnetic equator and decreased gradually in a symmetrical way on either side of the equator, which is consistent with a plasmasphere density decreasing with radial distance, such as, for example, $\rho_{e} \propto^{-3}$ [Allan and Poulter, 1992]. Using the electron density and spatial displacement data from the Cluster satellites at their perigees, the gradient of the electron density at the plasmapause may be estimated at $\sim 2.4 \times 10^{-2} \mathrm{~cm}^{-3} / \mathrm{km}$ near $r=4.3 R_{E}$. In order to estimate the gradient of the density more precisely, we can set a plasma density model for the plasmapause as $\rho_{e}=a r^{b}$. Using the same density and spatial displacement data when the Cluster satellites passed their perigees, the gradient of the electronic density around the plasmapause is then estimated to be $\sim 0.48 \mathrm{~cm}^{-3} / \mathrm{km}$ near $r=4.3 R_{E}$. This is significantly larger than the density gradient value above.

[22] Examination of the dynamic spectra of the EMIC waves in relation to the electron density profile shows that the waves only appeared in regions with significantly enhanced electron density and were confined mostly within the plasmapause (Figures 4 and 5). As described in section 4.3, the wave event seen at $\mathrm{C} 1, \mathrm{C} 2$, and $\mathrm{C} 4$ consisted of two trains of wave packets, separated at $\sim 2115 \mathrm{UT}$. Although $\mathrm{C} 1$ and $\mathrm{C} 2$ passed their perigees $\sim 4$ min earlier than $C 4$, the separation time is almost the same at the three spacecraft (Figure 5a). Even though C3 crossed its perigee $\sim 45 \mathrm{~min}$ later than the others, its first wave packet train began at $2118 \mathrm{UT}$, almost the same time the second wave packet train commenced at $\mathrm{C} 1, \mathrm{C} 2$, and $\mathrm{C} 4$. We can ascribe such a highly consistent timing among the spacecraft to the time taken for the EMIC waves to propagate at a group velocity of order $10^{3} \mathrm{~km} / \mathrm{s}$ [Allan and Poulter, 1992], which is much faster than the satellite speed $\sim 4.5 \mathrm{~km} / \mathrm{s}$. If we assume that the local Alfvén velocity is close to the group velocity in an $\mathrm{H}^{+}$plasma, then $V_{A}=B_{0} /\left(\mu_{0} \rho_{i}\right)^{0.5}$ at $2115 \mathrm{UT}$ is $\sim 1600 \mathrm{~km} /$ $\mathrm{s}$ at $\mathrm{C} 2$ and $\sim 1900 \mathrm{~km} / \mathrm{s}$ at C3. At these speeds, the waves will take 7.6 or $6.2 \mathrm{~s}$, respectively, to propagate from $\mathrm{C} 2$ to $\mathrm{C} 3$. Thus, the EMIC waves propagated very quickly from one satellite to another when they were located near the same field line (Figure 2). However, significant differences can still be seen between the wave spectra, that is, the first wave packet train increased in power with time, while for the second wave packet train, power increased from $\mathrm{C} 1, \mathrm{C} 2$ to $\mathrm{C} 4$ (Figure 5a). This may be explained by ion cyclotron instability theory arguing that cold plasma and anisotropic hot ion particles are necessarily required to generate and amplify EMIC waves [Cornwall, 1965; Kennel and Petschek, 1966].

[23] With respect to intersatellite comparisons, it is noted that the first wave packet train seen at C1, C2, and C4 was not seen by $\mathrm{C} 3$, as this satellite was still in the low-density plasmatrough with electron concentrations $<20 \mathrm{~cm}^{-3}$. Also, the wave trains after 2125 UT observed at C3 were not seen at C1, C2, and $\mathrm{C} 4$, which, by this time, had exited the plasmapause.

[24] The distances from $\mathrm{C} 1, \mathrm{C} 2, \mathrm{C} 3$, and $\mathrm{C} 4$ spacecraft to the Earth's center are 4.396, 4.264, 4.250, and 4.129, $R_{E}$, respectively, when they passed perigee (Table 1 and Figure 3 ). EMIC waves were not seen in regions with $L<\sim 4.13$ at C4 or $L>\sim 4.9$ at $\mathrm{C} 1$ (Figures 3 and 4 ). This suggests that the width of source region of the Pc1 waves in the radial direction may be estimated as $\sim 0.77 R_{E}$ from this event, obviously narrower than that derived by Anderson et al. [1996] in the outer magnetosphere using Active Magnetospheric Particle Tracer Explorers/Charge Composition Explorer (AMPTE/ CCE) satellite and Antarctic ground station data, where the source region width was estimated at $1-2 R_{E}$ (radial) at $\sim 9$ $R_{E}$. Recently, Usanova et al. [2008], using Time History of Events and Macroscale Interactions during Substorms (THEMIS) observations and Canadian ground data, have observed EMIC wave activity over a radial extent of $1.3 R_{E}$ at $\sim 5-6 R_{E}$. It seems that either the Cluster constellation can provide higher accuracy in estimating the radial width of the source region or the EMIC waves have a narrower radial width when propagating in the vicinity of the plasmapause.

\subsection{Reversal of Polarization}

[25] Theoretical work indicates that in a single-ion cold plasma, i.e., $\mathrm{e}^{-}-\mathrm{H}^{+}$plasma, EMIC waves propagate mainly in the guided left-hand mode and possibly in the unguided right-hand mode below the $\mathrm{H}^{+}$cyclotron frequency $\left(f_{\mathrm{H}+}\right)$ [Young et al., 1981; Rauch and Roux, 1982; Fraser, 1985]. When heavy ions such as $\mathrm{He}^{+}$and $\mathrm{O}^{+}$are present in the plasma, the wave modes become more complicated, with two additional resonances and mode coupling occurring for nonzero wave normal angle [Gurnett et al., 1965; Fraser et al., 1992, 2006]. The wave propagation is well described by consideration of the $\mathrm{He}^{+}$and $\mathrm{O}^{+}$characteristic frequencies, namely, the cyclotron frequencies $\left(f_{\mathrm{He}+}\right.$ and $\left.f_{\mathrm{O}+}\right)$, the cutoff frequencies ( $f_{\text {cfHe }}$ and $\left.f_{\text {cfo }}\right)$, the crossover frequencies $\left(f_{\mathrm{crHe}}\right.$ and $f_{\text {cro }}$ ), and the bi-ion hybrid frequencies ( $f_{\text {biHe }}$ and $\left.f_{\text {biO }}\right)$.

[26] Here the four Cluster spacecraft observed Pc1 waves simultaneously. As described in section 4.4, there are distinct polarization reversals seen by $\mathrm{C} 4$ and $\mathrm{C} 3$, which occurred at magnetic latitudes $\sim 14^{\circ}-16^{\circ}$ at $\mathrm{C} 4,-14^{\circ}$ to $-11^{\circ}$ and $11^{\circ}-$ $14^{\circ}$ at $\mathrm{C} 3$, left handed near the equator, and right handed farther away from the equator (Figures $6 \mathrm{a}$ and $6 \mathrm{~b}$ ). This may be expected to support the theoretical model predictions of polarization reversal in a multi-ion plasma and is consistent with observations from the Geostationary Satellites (GEOS 1 and 2) [Young et al., 1981; Rauch and Roux, 1982; Roux et al., 1982; Perraut et al., 1984]. Note that the polarization reversals occurred twice $(\sim 2120$ and $\sim 2200$ UT) for the waves seen at $\mathrm{C} 3$, symmetrical around the magnetic equator, and once ( $2120 \mathrm{UT})$ at C4. Around $2120 \mathrm{UT}$, the polarization experienced opposite senses of reversal but in opposite 


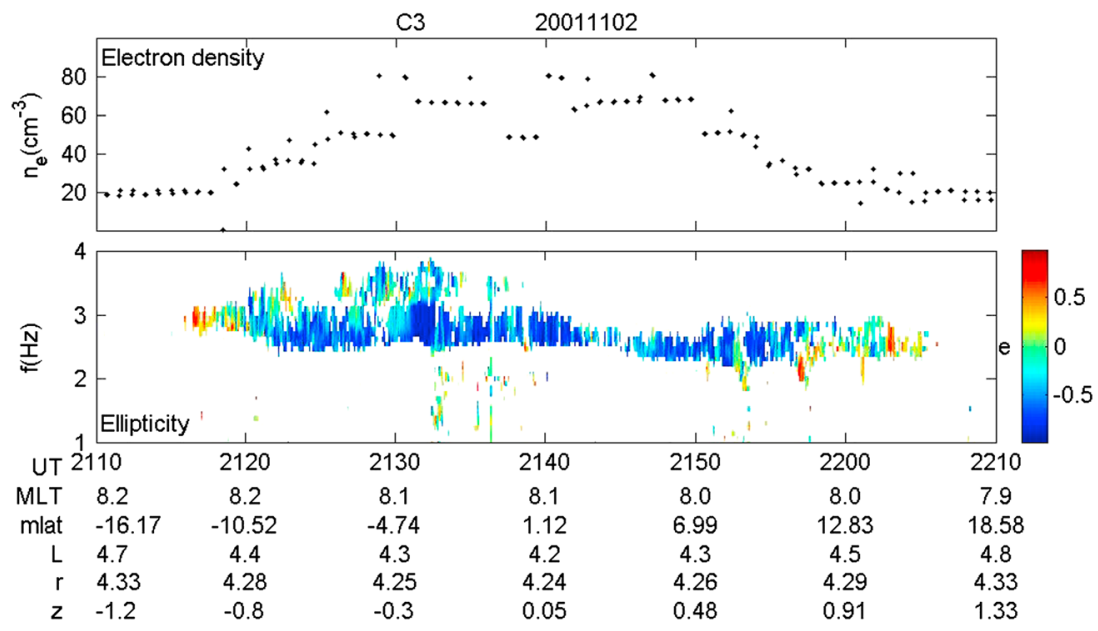

Figure 9. The WHISPER electron density and the ellipticity of the Pc1 waves observed at C3. The polarization was reversed near the plasmapause boundary where the electron density was significantly reduced.

directions, with $\mathrm{C} 4$ showing left hand to right hand and $\mathrm{C} 3$ right hand to left hand, as $\mathrm{C} 4$ and $\mathrm{C} 3$ moved away and toward the equator, respectively. On carefully examining the temporal variation of the polarization, a two or more minutes transition zone often appeared on the dynamic polarization spectra (Figures 6a and 6b), where the left- and right-hand polarizations coexist. At $\mathrm{C} 4$, the polarization transition region occurred over $\sim 2118-2122$ UT or $\sim 13.04^{\circ}-15.43^{\circ}$ MLAT, with nearly pure left hand below $\sim 13.04^{\circ}$ MLAT and predominantly right hand and linear beyond $\sim 15.43^{\circ}$ MLAT until the event ceased at $\sim 2125$ UT. At C3, the polarization transition region appeared over a smaller bandwidth and was more complicated over $2118-2120$ UT or $-11.66^{\circ}$ to $-10.52^{\circ}$ MLAT. Here the polarization was purely right hand below $-11.66^{\circ}$ MLAT and nearly pure left hand beyond $-10.52^{\circ}$ MLAT with frequencies $<3 \mathrm{~Hz}$. This situation seemed to be repeated for the last wave packet group seen at C3 as it was leaving the plasmapause (Figure 6b). Here linear and right-hand polarization continued over the lower frequencies with left hand at the upper frequencies. The transition may occur over 2157-2202 UT or $\sim 11.18^{\circ}-13.99^{\circ}$ MLAT. Again, the polarization is dominantly left hand for MLAT below $\sim 11.18^{\circ}$ and right hand beyond $\sim 13.99^{\circ}$. At this time, large wave normal angles $>60^{\circ}$ were observed (Figure 6b).

[27] As noted in section 4.3, the ellipticities of the EMIC waves seen at $\mathrm{C} 1$ and $\mathrm{C} 2$ are obviously different from those seen at $\mathrm{C} 4$, although $\mathrm{C} 1$ and $\mathrm{C} 2$ passed the same magnetic latitude and recorded the same two wave packet trains (Figure 6a). We ascribe this to the observation that $\mathrm{C} 1$ and $\mathrm{C} 2$ have passed tangentially through the plasmapause gradient, at the outer edge beyond the main plasmasphere, with a significantly lower plasma concentration (Figure 4). The total electron density was less than $\sim 30 \mathrm{~cm}^{-3}$ when the waves occurred at $\mathrm{C} 1$ and less than $\sim 40 \mathrm{~cm}^{-3}$ when seen at $\mathrm{C} 2$. No dominant polarization sense but a mix of left handed, right handed, and linear is seen at $\mathrm{C} 1$, even though it was located within $<10^{\circ}$ MLAT. At $\mathrm{C} 2$, the polarization is mainly left hand for the first wave packet train before 2115 UT with $\rho_{e}>30 \mathrm{~cm}^{-3}$ despite the absolute magnitude of the ellipticity being generally less than 0.5 .

[28] Figure 9 compares the variation in electron density and polarization at $\mathrm{C} 3$. We notice that the left-hand polarization seen at $\mathrm{C} 3$ and $\mathrm{C} 4$ occurred in the region with $\rho_{e}>\sim 30 \mathrm{~cm}^{-3}$, and the right-hand polarization occurred in the region with $\sim 20<\rho_{e}$ $\sim 30 \mathrm{~cm}^{-3}$, while the EMIC waves were absent when $\rho_{e}<\sim 20$ $\mathrm{cm}^{-3}$. In summary, the polarization sense as well as the propagation of the EMIC waves seem to be highly related with the cold plasma density. The presence of heavier ions such as $\mathrm{He}^{+}$ can cause polarization reversal [Young et al., 1981; Rauch and Roux, 1982], and this is discussed further in the next section.

\subsection{Propagation}

[29] Both the Poynting flux and wave normal directions plotted in Figures 7 and 8 show that the EMIC waves predominantly propagated away from the magnetic equator, suggesting that the wave source region was around the geomagnetic equator. These results are consistent with the generally accepted model that EMIC waves are generated in the magnetospheric equatorial region and do not support the bouncing wave packet model, which suggests that the wave packets seen in space should alternate propagation direction periodically [Tepley, 1964; Obayashi, 1965].

[30] Large angles between the wave propagation direction and the background magnetic field vector can still be seen during the time interval of the wave event, although the wave energy mainly propagated along the field lines. From the wave normal direction, we can see that the oblique propagation mainly occurred at latitudes above $\sim 10^{\circ}$ MLAT for the event. Near the magnetic latitude where the local bi-ion hybrid resonance frequency $\left(\mathrm{H}^{+} \sim \mathrm{He}^{+}\right)$may be matched, the waves tend to be reflected. The Poynting flux results clearly indicate that only nominal wave energy is turned back, and most of the wave energy propagates further along the field line.

[31] In order to explain the reasons for the cessation of the waves at the plasmapause, it is of interest to consider propagation of the waves from the equator and the associated plasma characteristic frequencies. Rather than considering a threeion plasma similar to Gurnett et al. [1965] and Fraser et al. [2006], for simplicity, we consider a less complicated twoion $\left(\mathrm{H}^{+}, \mathrm{He}^{+}\right)$plasma. This is appropriate since our wave event shows frequencies above the helium characteristic frequencies. The plasma characteristic frequencies for a two-ion plasma include the helium cyclotron frequency $\left(f_{\mathrm{He}+}\right)$, the helium-hydrogen bi-ion frequency $\left(f_{\mathrm{bi}}\right)$, the helium cutoff frequency $\left(f_{\mathrm{cf}}\right)$, and the helium crossover frequency $\left(f_{\mathrm{cr}}\right)$ 


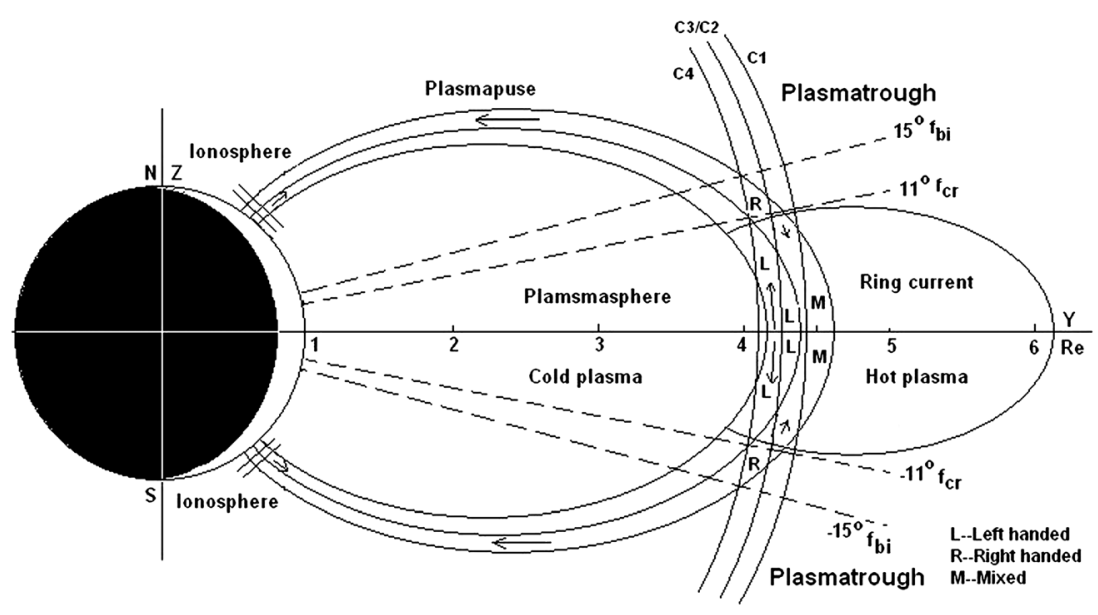

Figure 10. A schematic of the source region and propagation of EMIC waves at the plasmapause, which is mainly based on the wave event on 2 November 2001. The plasmapause is represented by three curves, respectively, for the inner/outer boundaries and the center region. The EMIC wave intensity is strongest around the center region and becomes weak when moving toward the boundaries. Left-hand polarization dominates around the center region and the inner side of it. Right-hand polarization appears close to the outer boundary and at higher latitudes. Mixed polarization appears between the outer boundary and the center region. $\mathrm{C} 3$ and $\mathrm{C} 2$ are denoted by one curve since their orbits are very close for this event.

[Gurnett et al., 1965; Fraser, 1985]. In order to compute these frequencies, we need to know the $\mathrm{He}^{+} / \mathrm{H}^{+}$cold ion abundance ratio which cannot be measured by the Cluster satellites since ion composition and density data for energies $<25 \mathrm{eV}$ were not available for this event. However, following Fraser et al. [2006], an approximate abundance ratio $(\eta)$ can be determined from the measured helium cutoff and cyclotron frequencies using the formula $f_{\mathrm{cf}}=(1+3 \eta) f_{\mathrm{He}^{+}}$, where the local cutoff and cyclotron frequencies were measured from the dynamic spectra shown in Figure 5 over 2110-2111 UT at C1, C2, and $\mathrm{C} 4$ and over 2124-2125 UT for C3. Here $f_{\mathrm{cf}}=2.4 \mathrm{~Hz}$ at all four satellites, and $f_{\mathrm{He}^{+}}=1.3,1.4,1.5$, and $1.6 \mathrm{~Hz}$ for $\mathrm{C} 1-\mathrm{C} 4$, respectively. The estimated abundance ratios calculated were $0.2821,0.2381,0.1825$, and 0.1458 at $\mathrm{C} 1-\mathrm{C} 4$, respectively. Using these frequencies, the crossover and biion frequencies were calculated from $f_{\mathrm{cr}}=(1+15 \eta)^{0.5} f_{\mathrm{He}+}$ and $f_{\mathrm{bi}}=\left[(1+3 \eta) /(1+3 \eta / 4]^{0.5} f_{\mathrm{He}+}\right.$, respectively.

[32] From the four characteristic frequencies overplotted in Figures $5 \mathrm{a}$ and $5 \mathrm{~b}$, it can be seen that the main EMIC wave emission band at all satellites falls in the band between the crossover and cutoff frequencies. This indicates that the waves will not undergo a polarization reversal when propagating away from the equator as suggested by Perraut et al. [1984], other than a few occasions where $f>f_{\text {cr }}$. Consequently, the left-hand polarized waves may eventually run into the cutoff frequency, and the wave energy is absorbed. This provides one possible argument for the cessation of the events near the plasmapause, such as seen in Figures 5a and 5b after 2120 UT at C1, C2, and $\mathrm{C} 4$ and after $2200 \mathrm{UT}$ at C3. However, the argument cannot explain the polarization reversals previously discussed. It is important to note that we have assumed the same $\mathrm{He}^{+} / \mathrm{H}^{+}$abundance ratio over the whole duration of the event.

[33] Although EMIC waves have been found in space over a wide range of $L$ values and even have higher occurrence in the outer magnetosphere [Anderson et al., 1992a, 1992b; Engebretson et al., 2002; Fraser and Nguyen, 2001], the EMIC wave event studied here was observed within enhanced electron density regions at $L \sim 4.2$, where the plasmapause is located under average magnetic conditions. Both the source region and the propagation path of the EMIC waves are confined to a limited narrow layer - the plasmapause. All the waves were seen by the Cluster satellites in the regions where electron density $\rho_{e}>\sim 20 \mathrm{~cm}^{-3}$, where the four spacecraft had ideal separations, allowing the observation of the waves simultaneously at different locations. We notice that the waves seen at $\mathrm{C} 1$ had their directions most stable and close to the field lines, suggesting that these waves are propagating in the plasmapause where there is a sufficient electron density and an electron density gradient, indicated by the WHISPER electron density observations (Figure 4), and supporting the plasmapause guiding of waves [Horne and Thorne, 1993]. The electron density distribution seen at $\mathrm{C} 1$ suggests that the waves existed in the region where $\sim 20<\rho_{e}<\sim 40 \mathrm{~cm}^{-3}$. In contrast, the waves at $\mathrm{C} 2, \mathrm{C} 3$, and $\mathrm{C} 4$ were less stable in their propagation directions and appeared to be more obliquely propagating, possibly more at the inner edge of the plasmapause with a higher electron density and a smaller electron density gradient, as indicated by a more smooth spatial variation. Thus, the plasma density and its gradient are crucial for the propagation as well as the excitation of the EMIC waves.

[34] Furthermore, the wave event was observed in a relatively broad plasmapause where the waves appeared to cease when electron densities decreased from 80 to $20 \mathrm{~cm}^{-3}$ over approximately $0.4 R_{E}$. This reduced level of cold plasma density may be insufficient to support the wave growth instability, which is dependent on cold plasma concentration and, possibly, the presence of $\mathrm{He}^{+}$and/or $\mathrm{O}^{+}$heavy ions. For example, Kozyra et al. [1984] showed that EMIC wave linear growth rates increased with an increasing cold plasma density.

\subsection{A Model for EMIC Waves at the Plasmapause}

[35] From consideration of the wave event studied using Cluster data, especially from C3, we can construct a model describing the wave generation and propagation process in a multi-ion plasma in the vicinity of the plasmapause. Since most of the wave energy observed is above the $\mathrm{He}^{+}$cyclotron 
frequency at the equator, it is sufficient to consider wave propagation in a two-ion $\mathrm{He}^{+}-\mathrm{H}^{+}$plasma embedded in a dipole geomagnetic field.

[36] Figure 10 shows a schematic of the process. Here only the Class III wave defined by Rauch and Roux [1982] with $f_{\mathrm{cf}}$ $f<f_{\text {cr }}$ is considered. These waves are generated within geomagnetic latitudes of $\pm 11^{\circ}$ [Loto'aniu et al., 2005] and may propagate parallel to the magnetic field in both directions within these bounds. Beyond $\pm 11^{\circ}$, the waves have been shown to propagate only away from the equator down to the corresponding ionosphere where they are transmitted to the ground. As noted by Young et al. [1981] and Rauch and Roux [1982], the waves propagate into an increasing geomagnetic field, and the wave frequency will eventually match the crossover frequency $f_{\mathrm{cr}}$, where a polarization reversal is seen. Here the waves are mode converted from left-hand ion cyclotron waves into right-hand polarized waves. The right-hand polarized waves with $f<f_{\text {cr }}$ then propagate through the ion cyclotron left-hand mode resonance and, eventually, $f=f_{\text {bi }}$, where, at the bi-ion resonance, the waves may be reflected and partially transmitted [Rauch and Roux, 1982; Perraut et al., 1984]. For the Cluster event considered here, there is evidence of $f_{\text {cr }}$ being encountered just before Cluster encounters the plasmapause and leaves the high-density plasmasphere. Cluster does not see the waves outside the plasmapause, and this may be a consequence of the plasmapause boundary on the cessation of the instability due to the lower cold plasma density in the plasmatrough. It is important to note that this specific scenario is based on observations where Cluster enters and leaves the plasmasphere and sees the EMIC waves only within this region.

\section{Summary}

[37] A typical EMIC wave event has been extensively analyzed using observations from the four Cluster satellites. The wave event was associated with the recovery phase of a moderate storm $(D s t=-106 \mathrm{nT})$. The main results can be summarized as follows.

[38] 1. The EMIC wave event had frequency in the range $1.8-3.5 \mathrm{~Hz}$ and was observed by the four Cluster spacecraft when passing through perigee $(L \sim 4.2)$ and moving northward on 2 November 2001 around 08 MLT.

[39] 2. The event occurred around the magnetic equatorial plane within the magnetic latitude range $\pm 18^{\circ}$ and with a duration of $50 \mathrm{~min}$.

[40] 3. Cold electron density data show that wave power was confined within the narrow shell of the plasmapause where the electron density decreased from 30 to 80 to $20 \mathrm{~cm}^{-3}$. The radial scale size of the wave region is estimated at $\sim 0.77 R_{E}$.

[41] 4. Wave polarization was dominantly left hand in the equatorial region and inside the source region but right hand at the outer edge of the plasmapause and at higher latitudes.

[42] 5. Poynting flux and minimum variance analyses indicate that wave energy was mainly transported along field lines toward higher latitudes, though oblique propagation was seen around the equatorial region.

[43] 6 . These results suggest that the plasma density and its gradient play a significant role in confining the wave source region and affecting the wave properties, which will help understand the wave generation and propagation mechanisms in the plasma environment in the magnetosphere. Theoretical computations are needed to understand the propagation of waves from the plasmasphere through the plasmapause boundary into the magnetosphere.

[44] Although this study indicates that the EMIC waves seen by Cluster do not appear to propagate along the geomagnetic field line path outside the plasmapause, it would be interesting in a future study to look for such events in conjugate regions on the ground.

[45] Acknowledgments. The work at the University of Newcastle was supported by Australian Research Council Discovery Project grant DP0772504 and Linkage International grant LX0882515, by an Australia Endeavor Postgraduate Research Scholarship, and by a University of Newcastle Postgraduate Research Scholarship. The work at the Polar Research Institute of China was supported by the 973 Project, Ministry of Science and Technology (grant 201005017); the Shanghai Pujiang Talent Project (grant 12PJ1409200); the Ocean Public Welfare Scientific Research Project, State Oceanic Administration, China (grant 201005017); and the National Natural Science Foundation of China (grants 40890164 and 41031064). Cluster satellite data were provided by the ESA Cluster Active Archive. Magnetic field data, electric field data, CIS ion data, and WHISPER electron density data were made available by the Cluster FGM team, STAFF team/EDI team, CIS team, and WHISPER team, respectively. The ACE satellite data were provided by the Coordinated Data Analysis of NSSDC, U.S.; IMF data by R. Lepping from NASA-GSFC; and solar wind data by K. Ogilvie, NASA-GSFC. Dst data were provided by the WDC-2 for magnetism at Kyoto University, Japan.

[46] Masaki Fujimoto thanks Michael Denton for his assistance in evaluating this paper.

\section{References}

Allan, W., and E. M. Poulter (1992), ULF waves-Their relationship to the structure of the Earth's magnetosphere, Rep. Prog. Phys., 55, 533-598.

Anderson, B. J., R. E. Erlandson, and L. J. Zanetti (1992a), A statistical study of Pc 1-2 magnetic pulsations in the equatorial magnetosphere: 1. Equatorial occurrence distributions, J. Geophys. Res., 97(A3), 3075-3088, doi:10.1029/ 91JA02706.

Anderson, B. J., R. E. Erlandson, and L. J. Zanetti (1992b), A statistical study of Pc 1-2 magnetic pulsations in the equatorial magnetosphere: 2 . Wave properties, J. Geophys. Res., 97(A3), 3089-3101, doi:10.1029/ 91JA2697.

Anderson, B. J., R. E. Erlandson, M. J. Engebretson, J. Alford, and R. L. Arnoldy (1996), Source region of 0.2 to $1.0 \mathrm{~Hz}$ geomagnetic pulsation bursts, Geophys. Res. Lett., 23(7), 769-772, doi:10.1029/96GL00659.

Balogh, A., et al. (1997), The Cluster magnetic field investigation, Space Sci. Rev., 79, 65.

Borovsky, J. E., and M. H. Denton (2008), A statistical look at plasmaspheric drainage plumes, J. Geophys. Res., 113, A09221, doi:10.1029/ 2007JA012,994.

Carpenter, D. L. (1963), Whistler evidence of a 'knee' in the magnetospheric ionization density profile, J. Geophys. Res., 68(6), 1675-1682, doi:10.1029/JZ068i006p01675.

Carpenter, D. L., and R. R. Anderson (1992), An ISEE 1 whistler model of equatorial electron density in the magnetosphere, J. Geophys. Res., 97(A2), 1097-1108, doi:10.1029/91JA01548.

Chappell, C. R. (1974), Detached plasma regions in the magnetosphere, J. Geophys. Res., 79(13), 1861-1870, doi:10.1029/JA079i013p01861.

Cornwall, J. M. (1965), Cyclotron instabilities and electromagnetic emission in the ultra low frequency and very low frequency ranges, J. Geophys. Res., 70(1), 61-69, doi:10.1029/JZ070i001p00061.

Cornwall, J. M., F. V. Coroniti, and R. M. Thorne (1970), Turbulent loss of ring-current protons, J. Geophys. Res., 75, 4699-4709.

Décréau, P. M. E. (2001), Early results from the WHISPER instrument on Cluster: An overview, Ann. Geophys., 19, 1241-1258.

Engebretson, M. J., W. K. Peterson, J. L. Posch, M. R. Klatt, B. J. Anderson, C. T. Russell, H. J. Singer, R. L. Arnoldy, and H. Fukunishi (2002), Observations of two types of Pc 1-2 pulsations in the outer dayside magnetosphere, J. Geophys. Res., 107(A12), 1451, doi:10.1029/ 2001JA000198.

Erlandson, R. E., B. J. Anderson, and L. J. Zanetti (1992), Viking magnetic and electric field observations of periodic Pc 1 waves: Pearl pulsations, J. Geophys. Res., 97(A10), 14,823-14,832, doi:10.1029/ 92JA00838.

Erlandson, R. E., K. Mursula, and T. Bösinger (1996), Simultaneous groundsatellite observations of structured Pc 1 pulsations, J. Geophys. Res., 101(A12), 27,149-27,156, doi:10.1029/96JA02645. 


\section{LIU ET AL.: EMIC WAVES NEAR THE PLASMAPAUSE}

Escoubet, C., M. Fehringer, and M. Goldstein (2001), The Cluster mission, Ann. Geophys., 19, 1197-1200.

Fowler, R. A., B. J. Kotick, and R. D. Elliot (1967), Polarization analysis of natural and artificially induced geomagnetic pulsations, J. Geophys. Res., 72(11), 2871-2883, doi:10.1029/JZ072i011p02871.

Fraser, B. J. (1985), Observations of ion cyclotron waves near synchronous orbit and on the ground, Space Sci. Rev., 42, 357-374.

Fraser, B. J., and T. S. Nguyen (2001), Is the plasmapause a preferred source region of electromagnetic ion cyclotron waves in the magnetosphere?, J. Atmos. Sol. Terr. Phys., 63, 1225.

Fraser, B. J., J. C. Samson, R. L. McPherron, and C. T. Russell (1992), Electromagnetic ion cyclotron waves observed near the oxygen cyclotron frequency by ISEE-1 and 2, J. Geophys. Res., 97(A3), 3063-3074, doi:10.1029/91JA02447.

Fraser, B. J., H. J. Singer and T. M. Loto' aniu (2006), Electromagnetic ion cyclotron waves in the magnetosphere, in Magnetospheric ULF Waves: Synthesis and New Directions, Geophys. Monogr. Ser., vol. 169, edited by K. Takahashi, et al., pp. 195-212, AGU, Washington, D. C., doi:10.1029/169GM13.

Gurnett, D. A., S. D. Shawhan, N. M. Brice, and R. L. Smith (1965), Ion cyclotron whistlers, J. Geophys. Res., 70(7), 1665-1688.

Gustafsson, G. M., et al. (2001), First results of electric field and density observations by Cluster EFW based on initial months of operation, Ann. Geophys., 19, 1219-1240.

Horne, R. B., and R. M. Thorne (1993), On the preferred source location for the convective amplification of ion cyclotron waves, J. Geophys. Res., 98(A6), 9233-9247, doi:10.1029/92JA02972.

Hu, Y. D., B. J. Fraser, and J. V. Olson (1990), Amplification of electromagnetic ion cyclotron waves along a wave path in the Earth's multicomponent magnetosphere, Geophys. Res. Lett., 17(8), 1053-1056, doi:10.1029/GL017i008p01053.

Kennel, C. F., and H. E. Petschek (1966), Limit on stably trapped particle fluxes, J. Geophys. Res., 71(1), 1-28, doi:10.1029/JZ071i001p00001.

Kozyra, J. U., T. E. Cravens, A. F. Nagy, and E. Fontheim (1984), Effects of energetic heavy ions on electromagnetic ion cyclotron wave generation in the plasmapause region, J. Geophys. Res., 89(A4), 2217-2233.

Lemaire, J. F., and K. I. Gringauz (1998), The Earth's Plasmasphere, Cambridge Univ. Press, New York.

Loto'aniu, T. M., B. J. Fraser, and C. L. Waters (2005), Propagation of electromagnetic ion cyclotron wave energy in the magnetosphere, J. Geophys. Res., 110, A07214, doi:10.1029/2004JA010816.

Mauk, B. H. (1982), Helium resonance and dispersion effects on geostationary Alfven/ion cyclotron waves, J. Geophys. Res., 87(A11), 9107-9119, doi:10.1029/JA087iA11p09107.

Mauk, B. H., and R. L. McPherron (1980), An experimental test of the electromagnetic ion cyclotron instability within the Earth's magnetosphere, Phys. Fluids, 23(10), 2111, doi:10.1063/1.862873.

Moullard, O., A. Masson, H. Laakso, M. Parrot, P. Décréau, O. Santolik, and M. Andre (2002), Density modulated whistler mode emissions observed near the plasmapause, Geophys. Res. Lett., 29(20), 1975, doi: 10.1029/ 2002GL015101.
Nishida, A. (1966), Formation of plasmapause or magnetospheric plasma knee, by the combined action of magnetospheric convection and plasma escape from the tail, J. Geophys. Res., 71(23), 5669-5679, doi:10.1029/ JZ07i023p05669.

Obayashi, T. (1965), Hydromagnetic whistlers, J. Geophys. Res., 70(5), 1069-1078, doi:10.1029/JZ070i005p01069.

Perraut, S., R. Gendrin, A. Roux, and C. de Villedary (1984), Ion cyclotron waves: Direct comparison between ground-based measurements and observations in the source region, J. Geophys. Res., 89(A1), 195-202, doi:10.1029/JA089iA01p00195.

Pickett, J. S., et al. (2010), Cluster observations of EMIC triggered emissions in association with Pc1 waves near the Earth's plasmapause, Geophys. Res. Lett., 37, L09104, doi:10.1029/ 2010GL042648.

Rauch, J. L., and A. Roux (1982), Ray tracing of ULF waves in a multicomponent magnetospheric plasma: Consequences for the generation mechanism of ion cyclotron waves, J. Geophys. Res., 87(A10), 8191-8198, doi:10.1029/HA087iA10p08191.

Remè, H., et al. (2001), First multispacecraft ion measurements in and near the Earth's magnetosphere with the identical Cluster ion spectrometry (CIS) experiment., Ann. Geophys., 19, 1303-1354.

Roux, C., S. Perraut, J. L. Rauch, C. D. Villedary, G. Kremser, A. Korth, and D. T. Yong (1982), Wave-particle interaction near !He+ observed on board GEOS 1 and 2: 2. Generation of ion cyclotron waves and heating of He+ ions, J. Geophys. Res., 87, 8174-8190.

Sandel, B. R., R. A. King, W. T. Forrester, D. L. Gallagher, A. L. Broadfoot, and C. C. Curtis (2001), Initial results from the IMAGE Extreme Ultraviolet Imager, Geophys. Res. Lett., 28(8), 1439-1442, doi:10.1029/ 2001GL012885.

Sonnerup, B. U., and L. J. Cahill (1967), Magnetopause structure and attitude from Explorer 12 observations, J. Geophys. Res., 72(1), 171-183, doi:10.1029/HZ072i001p00171.

Tepley, L. (1964), Low-latitude observations of fine-structured hydromagnetic emissions, J. Geophys. Res., 69, 2273-2290.

Tsyganenko, N. A. (1996), Effects of the solar wind conditions on the global magnetospheric configuration as deduced from data-based field models, Eur. Space Agency Spec. Publ., ESA SP-389, 181 pp.

Usanova, M. E., I. R. Mann, I. J. Rae, Z. C. Kale, V. Angelopoulos, J. W. Bonnell, K.-H. Glassmeier, H. U. Auster, and H. J. Singer (2008), Multipoint observations of magnetospheric compression related EMIC Pc 1 waves by THEMIS and CARISMA, Geophys. Res. Lett., 35, L17S25, doi:10.1029/2008GL034458.

Usanova, M. E., et al. (2010), Conjugate ground and multisatellite observations of compression-related EMIC Pc1 waves and associated proton precipitation, J. Geophys. Res., 115, A07208, doi:10.1029/ 2009JA014935.

Young, D. T., S. Perraut, A. Roux, C. D. Villedary, R. Gendrin, A. Korth, G. Kremser, and D. Jones (1981), Wave-particle interactions near $\Omega_{\mathrm{He}^{+}}$ observed on GEOS 1 and 2: 1. Propagation of ion cyclotron waves in $\mathrm{He}^{+}$-rich plasma, J. Geophys. Res., 86(A8), 6755-6772, doi:10.1029/ JA086iA08p06755. 